\title{
La Administración como responsable de infracciones contra la competencia cuando actúa como poder público
}

\author{
Carmen Martín Fernández
}

Investigadora en Área de Derecho Administrativo

Universidad de Córdoba

I. INTRODUCGIÓN. II. GASO DEL GÁRTEL DE LOS PRODUGTORES DE VINO DE JEREZ. 1. La resolución de la Comisión Nacional de la Competencia. 2. La sentencia de la Audiencia Nacional. 3. La sentencia del Tribunal Supremo. III. CASO DEL PUERTO DE BARCELONA. 1. La resolución de la Comisión Nacional de la Competencia. 2. La sentencia de la Audiencia Nacional. IV. EL DEBATE DOCTRINAL. V. LA ADMINISTRACIÓN Y SU INCIDENGIA EN EL MERGADO: COMO OPERADOR EGONÓMICO Y COMO PODER PÚBLICO. VI. LA ADMINISTRAGIÓN Y LAS CONDUGTAS EXENTAS POR LEY. VII. LA LEGITIMAGIÓN DE LAS AUTORIDADES DE DEFENSA DE LA GOMPETENCIA PARA IMPUGNAR ACTUACIONES ADMINISTRATIVAS CONTRARIAS A LA COMPETENCIA. VIII. LA RESPONSABILIDAD DE LAS ADMINISTRACIONES EN CONCEPTO DE "FACILITADOR" DE INFRACGIONES CONTRA LA COMPETENCIA. 1. La formación del concepto de facilitador en la jurisprudencia europea. 2. Posibles objeciones a la recepción de la responsabilidad por facilitar infracciones contra la competencia en el Derecho español. 3. La aplicación del concepto de facilitador a la Administración. IX. CONCLUSIONES. X. BIBLIOGRAFÍA.

\section{RESUMEN}

Ya no es novedoso que las autoridades de defensa de la competencia puedan sancionar a las personas públicas, incluso a las Administraciones, por infracciones contra la competencia. Pero hasta ahora eso sólo se aceptaba en tanto que las Administraciones o sus entes institucionales actuaran como empresas. Hace algunos años la Comisión Nacional de la Competencia decidió que también cabía sancionar a las Administraciones cuando, actuando como poderes públicos, restringen la competencia. Lo hizo, además, considerando que la Administración actuaba como "facilitador" de la infracción, figura en sí misma cuestionable. Ahora los Tribunales han 
aceptado aquella construcción. En este trabajo se da cuenta de aquellas resoluciones y de estas sentencias, del debate que han suscitado y de sus pros y contras.

\section{PALABRAS CLAVE}

Administración pública, defensa de la competencia, sanciones administrativas, responsables de las infracciones.

\section{ABSTRACT}

It is no longer new that the competition authorities can sanction public persons, including the Administrations, for infractions against competition. But up to now, that was only accepted as long as the Administrations acted as company. Some years ago, the National Competition Commission decided that it was also possible to punish the Administrations when, acting as public authorities, their actions restrict competition. He did it, also, considering that the Administration acted as "facilitator" of the infraction, figure in itself questionable. Now, the Courts have accepted that construction. In this paper, these resolutions and judgments and the debate generated by them are analysed together with the pros and cons of their ideas.

\section{KEYWORDS}

Public Administration, defence of competition, administrative sanctions, responsible for infractions.

\section{INTRODUCGIÓN}

Numerosos colegios profesionales y consejos reguladores de las denominaciones de origen han sido declarados infractores de las normas de defensa de la competencia porque, a pesar de ser entidades públicas que tienen ciertas potestades de regulación del sector en que actúan, agrupan en su seno a sujetos privados que actúan en el mercado persiguiendo sus propios intereses, y en algunas ocasiones, intervienen en acuerdos anticompetitivos, normalmente, de fijación de precios y condiciones comerciales, de limitación de la producción o de reparto del mercado. En estos casos, la conducta llevada a cabo por las mencionadas corporaciones de Derecho Público es idéntica a la conducta de los operadores económicos privados, por lo que no existe ningún impedimento para que también sean sancionadas por la CNC.

Sin embargo, de un tiempo a esta parte, la autoridad de la competencia española parece haber ido aún más allá al poner de manifiesto que es la propia Administración Pública, y no sólo las corporaciones o entidades de Derecho Público no territoriales, la que puede ser sujeto infractor de la normativa de competencia, incluso cuando sin desarrollar una actividad económica realiza, al margen de toda habilitación normativa, actuaciones que amparan o refuerzan los efectos restrictivos 
de conductas realizadas por los operadores económicos. Tal ha sido el caso de la Junta de Andalucía, sancionada por la resolución de la GNC de 6 de octubre de 2011, y el de la autoridad portuaria de Barcelona, sancionada por la GNC en su resolución de 10 de enero de 2013, ambas por facilitar infracciones administrativas de competencia. En ninguno de los casos la Administración Pública actuaba como operador económico en el mercado de referencia, pero ello no ha obstado para que la autoridad de la competencia las haya sancionado por participar en las prácticas anticompetitivas de otros, pues sin su actuación, auxiliar pero esencial para los objetivos del cártel, las infracciones no se habrían cometido, o al menos, no tan fácilmente.

A pesar de esta tendencia en las resoluciones de la GNC, actual CNMC, la cuestión no está exenta de polémica, por lo que surgen opiniones discrepantes en la doctrina y también en el ámbito judicial, donde la Audiencia Nacional y el Tribunal Supremo fallan en sentidos diferentes cuando se enfrentan por primera vez al mencionado cambio de criterio. Se trata ahora de analizar los casos mencionados para, acto seguido, poner de manifiesto las principales líneas doctrinales enfrentadas, así como las cuestiones teóricas implicadas en el asunto.

\section{EL GASO DEL CÁRTEL DE LOS PRODUCTORES DE VINO DE JEREZ Y DE LA CONSEJERÍA DE AGRICULTURA Y PESCA}

\section{La resolución de la Comisión Nacional de la Competencia}

La Comisión Nacional de la Competencia (CNC) mediante resolución de 6 de octubre de 2011, declaró a la Consejería de Agricultura y Pesca (en adelante, CAP) de la Junta de Andalucía, junto con otros operadores económicos (asociaciones de empresarios y agricultores, Consejo Regulador de la Denominación de Origen), responsables de infringir normas de Derecho de la competencia, concretamente el art. 1 de la Ley 15/2007, de Defensa de la Competencia (LDC) y el art. 101 del Tratado de Funcionamiento de la Unión Europea (TFUE), por llevar a cabo acuerdos de fijación de precios de la uva y el mosto.

Ello porque la CAP había firmado el "Plan Estratégico para el Marco de Jerez" y había presidido la Comisión de Seguimiento creada a tal efecto; en suma, porque había participado en un acuerdo de fijación de precios, conducta anticompetitiva expresamente prohibida por los artículos anteriormente mencionados. La GNC declaró responsable de la infracción a la CAP con tres argumentos:

a) Sobre el sometimiento de las Administraciones Públicas al Derecho de la Competencia: la GNC sostuvo que la Administración Pública se encuentra su- 
jeta en su actuación a la normativa de Derecho de la competencia, incluso cuando ejerce funciones públicas. Para ello se basó en algunas sentencias del Tribunal Supremo, en las que se declaraba, obiter dicta, que ni siquiera el ejercicio de funciones públicas exime a la Administración de su sometimiento a la $\mathrm{LDC}^{1}$. Y, acto seguido, puntualizó que las potestades públicas que ostenta la CAP para la ordenación del sector agrario, ganadero y agroalimentario no la habilitan para realizar cualquier tipo de actuación, sino que, conforme al mandato constitucional, toda Administración debe actuar respetando la Ley y el Derecho, lo cual incluye la normativa de competencia. Según la CNC, en el presente caso lo que ocurrió es que la CAP, al supuesto amparo de una potestad pública, realizó una conducta claramente anticompetitiva. En definitiva, destacó que lo más relevante de dicha jurisprudencia es que el TS acepta que el ejercicio inadecuado de prerrogativas públicas puede ser sancionado por la GNC. Aunque la GNC no es competente para revisar actos administrativos, sí que ostenta competencia para sancionar las conductas anticompetitivas realizadas por cualquier sujeto, incluida la Administración Pública. Todo ello sin perjuicio de que, por otra parte, quepa impugnar ante la jurisdicción contencioso-administrativa el mismo acto o actuación administrativa por el que la Administración es sancionada y de que esa jurisdicción la anule.

b) Sobre la forma de participación de la CAP en la infracción: la CNC sostuvo que la CAP había desempeñado una conducta propia de la figura del "facilitador" de infracciones (figura ya acogida alguna vez por la jurisprudencia de la Unión Europea), pues no sólo había firmado el mencionado Plan y presidido la Comisión de Seguimiento, sino que también había velado por la adecuada ejecución del acuerdo de fijación de precios, llegando a proponer su revisión. En suma, su actuación tuvo entidad propia y resultó decisiva para la consecución del objetivo común compartido por los operadores del mercado que participaron junto a ella en el acuerdo anticompetitivo.

c) Sobre la innecesariedad de intervenir como operador económico en el mercado: la CNG se planteó la cuestión de si la condición de operador económico es imprescindible para que la Administración pueda ser declarada infractora de la LDG, y llegó a la conclusión de que no lo es, pues, en cualquier caso, lo

Buena muestra de ello es la STS de 4 de noviembre de 2008, recurso de casación 5837/2005, en la que el Alto Tribunal declaró que "ni el ejercicio de funciones públicas exime a un Colegio Profesional -ni a la Administración Pública en general- de su sometimiento a la legislación de defensa de la competencia, ni la habilitación legal con que necesariamente actúan las Administraciones Públicas o las entidades que ejerzan funciones públicas implica, por su sola existencia, la aplicación del artículo 2 de la Ley de Defensa de la Competencia" (actual art. 4 LDC). 
relevante no es la naturaleza jurídica del sujeto, sino la virtualidad de su conducta para producir efectos anticompetitivos en el mercado.

Con esos tres argumentos la CNC concluyó que la conducta de la CAP podía subsumirse en el art. 1 LDG y en el art. 101 TFUE, por lo que resultaba plenamente responsable de la infracción. Sin embargo, sin cambiar un ápice nada de lo anterior, finalmente optó por no sancionar a la CAP porque su resolución suponía un cambio de criterio respecto a anteriores expedientes en los que, en situaciones similares o hasta idénticas, no se había considerado que la Administración fuese responsable de infracciones contra la competencia. En definitiva, se declara a la CAP responsable de la infracción, pero no se le impone sanción por lo novedoso de la interpretación $\operatorname{acogida}^{2}$.

Frente a la resolución adoptada por la mayoría, la consejera María Jesús González López formuló un voto particular. Partiendo de que sólo pueden cometer infracciones contra la competencia los operadores económicos y de que las Administraciones sólo pueden cometerlas cuando actúan como tales, sostuvo que la extralimitación de una Administración Pública en el ejercicio de sus prerrogativas no conlleva su consideración como operador económico; y que, por ende, tampoco puede conllevar su declaración de responsabilidad por la GNC. Por el contrario, corresponde a la jurisdicción contencioso-administrativa, en virtud del antiguo art. 12.3 LDG y del actual art. 5.4 de la Ley 3/2013, de creación de la Comisión Nacional de los Mercados y la Competencia (LCNMC), controlar la legalidad de su actuación ${ }^{3}$.

\section{La sentencia de la Audiencia Nacional}

La Junta de Andalucía interpuso recurso contra la resolución de la CNC de 6 de octubre de 2011, que fue estimado por la SAN de 16 de julio de 2013, recurso contencioso-administrativo n ${ }^{\circ}$ 626/2011. En esta sentencia, la Audiencia Nacional declaró que la CAP no podía ser considerada responsable de la infracción ni sancionada por la CNC porque no intervino como operador económico, sino en el ejercicio

\footnotetext{
Posteriormente, la CNMC ha seguido actuando de la misma forma. En la Resolución de 27 de septiembre de 2013 (expte. VS/0134/10, Puerto de Valencia) también ha declarado la responsabilidad de una Administración pública, concretamente de la Consellería de Infraestructuras y Transportes de la Generalitat Valenciana por facilitar y fomentar las prácticas colusorias de diversos operadores del Puerto de Valencia, pero ha resuelto no sancionarla. Apud ORTEGA BERNARDO, Julia, “iSe puede sancionar a la Administración en el ámbito de la Defensa de la Competencia?", Almacén de Derecho, 31 de enero de 2017, recuperado de http://almacendederecho.org/

3 De igual modo, la Agencia de Defensa de la Competencia de Andalucía consideró que, a pesar de lo reprochable de la conducta de la CAP, la misma no podía calificarse de económica, por lo que no podía ser sancionada por la CNC por incumplimiento del art. 101 TFUE, precepto dirigido únicamente a las empresas.
} 
de potestades públicas, cuya extralimitación no puede conllevar que la Administración pase a ser un potencial sujeto infractor de la normativa de competencia. La SAN consideró que "para que una conducta objetivamente reprochable pueda ser sancionada por la autoridad de defensa de la competencia es necesario que el sujeto infractor esté incluido en el ámbito subjetivo de aplicación de las normas de defensa de la competencia", lo que no sería el caso.

La SAN hizo referencia a jurisprudencia europea, conforme a la que «empresa» es cualquier entidad que ejerce una actividad económica, con independencia de su estatuto jurídico y modo de financiación; entendiendo por «actividad económica» cualquier actividad consistente en ofrecer bienes o servicios en un determinado mercado. Por lo tanto, se deduce que incluso el propio Estado o un organismo estatal pueden actuar como empresa. Pero no tienen carácter económico las actividades que se vinculan al ejercicio de prerrogativas de poder público, por lo que un sujeto de Derecho, y especialmente un organismo público, puede considerarse empresa sólo en relación a una parte de sus actividades, cuando estas puedan considerarse económicas, pero no cuando se trata de ejercicio de potestades públicas ${ }^{4}$. Todo ello no supone que la conducta de la CAP no sea ilícita, sino únicamente que el cauce de actuación no había sido el adecuado, pues la CNG resulta incompetente, correspondiendo juzgar esa actuación de la Administración a la jurisdicción contencioso-administrativa ex art. 12.3 LDG y actual art. 5.4 LCNMC. Por este motivo, la SAN de 16 de julio de 2013 anuló la resolución de la GNC en lo relativo a la responsabilidad sancionadora de la CAP.

STJUE de 12 de julio de 2012 (caso Compass-Datenbank): sentencia dictada en respuesta a una solicitud de decisión prejudicial que tenía por objeto la interpretación del art. 102 TFUE, en el marco de un litigio entre la República de Austria y Compass-Datenbank, una sociedad austriaca de responsabilidad limitada que explotaba una base de datos económicos con el fin de prestar servicios de información, para lo que necesitaba acceso a una versión actualizada de los asientos del Firmenbuch (Registro Mercantil). Lo que nos interesa en este supuesto es que el TJUE afirmó que, si la protección sui generis de la que goza la autoridad pública como creadora de una base de datos, constituye una actividad económica, dicha autoridad pública, en el ejercicio de esa actividad, debe considerarse una empresa a efectos del art. 102 TFUE. Y esto se debe a que la jurisprudencia europea sobre Derecho de la competencia considera que "empresa" es cualquier entidad que ejerce una actividad económica, con independencia de su estatuto jurídico y modo de financiación; entendiendo por "actividad económica" cualquier actividad consistente en ofrecer bienes o servicios en un determinado mercado. Por lo tanto, se deduce que incluso la propia Administración o un organismo público puede actuar como empresa. Pero no tienen carácter económico las actividades que se vinculan al ejercicio de prerrogativas de poder público, por lo que las personas jurídicas públicas pueden considerarse empresas sólo en relación a una parte de sus actividades, las que pueden considerarse actividades económicas. 


\section{La sentencia del Tribunal Supremo}

La Administración del Estado interpuso recurso contra esta SAN con un único motivo de casación: aunque la CAP de la Junta de Andalucía no interviniera como operador económico, participó activamente en el acuerdo de fijación de precios, por lo que, conforme al principio de legalidad de la actuación administrativa, debía de poder ser controlada, y eventualmente sancionada, por la CNC; además, decía, al tratarse de una actividad material y no de disposiciones generales o actos administrativos, no podía llevarse a cabo el control por la jurisdicción contencioso-administrativa.

La STS de 18 de julio de 2016 (recurso de casación n 2946/2013), estimó dicho motivo pues consideró que del art. 1 LDG no se deduce que las entidades jurídico-públicas no puedan ser posibles sujetos infractores, sino más bien al contrario, pues el art. 61 de la misma ley alude tanto a personas físicas como jurídicas, sin excluir a las públicas. En definitiva, el Alto Tribunal consideró, al igual que la CNC, que lo relevante para la sujeción a la normativa de la competencia no es la condición jurídica del sujeto, sino la virtualidad de su conducta para ejercer influencia en el mercado y perjudicar la libertad de competencia.

Además, en relación con la Administración Pública y la exclusión contemplada en el art. 4 LDC, puntualizó que no basta con actuar "invocando el ejercicio de una competencia legalmente atribuida”, sino que debe operar efectivamente la cláusula de exclusión, por lo que debe existir una ley que autorice, e incluso obligue, a la Administración a actuar en sentido anticompetitivo, en favor de otros valores del ordenamiento jurídico.

Como consecuencia, la Sala declaró ajustada a Derecho la resolución de la CNC y, por tanto, confirmó que la CAP era responsable de la infracción por el cartel de los vinos de Jerez.

\section{EL CASO DEL PUERTO DE BARGELONA}

\section{Resolución de la Comisión Nacional de la Competencia}

La CNG, en su resolución de 10 de enero de 2013 (expediente sancionador S/0293/10 TRANSCONT), declaró responsable a la Autoridad Portuaria de Barcelona (en adelante, APB), junto con otros operadores económicos privados (ALTC y CONTRAPORT, antes TRANSCONT), por infringir el art. 1 LDG y el art. 101 TFUE al llevar a cabo acuerdos restrictivos de la competencia.

Todo comenzó cuando, el 10 de agosto de 2010, la GNG recibió un escrito de la misma APB, según el cual dos asociaciones de transportistas (TRANSCONT y 
ALTG) estaban realizando una serie de prácticas contrarias a la libre competencia para boicotear los depósitos de contenedores de TYMSA y SETEMAR, que consistían básicamente en la remisión de correos electrónicos a distintos consignatarios y operadores portuarios para indicarles con quién contratar o no el trasporte terrestre en el Puerto de Barcelona. Ante ello, la Dirección de Investigación llevó a cabo investigaciones para comprobar si realmente se estaban produciendo prácticas restrictivas prohibidas por el artículo 1 LDG y por el artículo 101 TFUE. A consecuencia de las mismas, la Dirección de Investigación formuló un pliego de concreción de hechos en el que consideró probados los siguientes:

- La creación de "observatorios de costes" para el establecimiento de las tarifas que debían aplicar los transportistas autónomos a las empresas de transporte y éstas a sus clientes.

- El establecimiento de los precios anuales de los servicios a prestar, de sus actualizaciones según IPC, del momento en el que aplicar las actualizaciones, así como de otros aspectos. En este sentido, la participación de la APB consistía en la elaboración los documentos base para calcular el coste del transporte.

- Establecimiento de los rappels o descuentos a aplicar sobre las tarifas.

- Establecimientos de periodos máximos de pago entre las empresas de transporte y los autónomos.

- La existencia de conversaciones dirigidas a repartir la carga de trabajo entre los autónomos.

- La existencia de comunicaciones entre los "observatorios de costes" y las asociaciones de clientes finales para la aplicación de las tarifas establecidas.

Se acreditaba así la existencia de un acuerdo de fijación de precios y condiciones comerciales (plazos y formas de pago), de limitación o control de la producción y de reparto de mercado en el transporte por carretera de contenedores con origen y/o destino en el Puerto de Barcelona, entre enero de 2006 y marzo de 2011.

Para sancionar dicha conducta, la CNG consideró de aplicación el art.1 LDC (aunque los hechos comenzaron en 2006, se aplicó únicamente la Ley 15/2007 y no la Ley 16/1989 de Defensa de la Competencia, por ser la segunda en el tiempo más beneficiosa para las entidades imputadas) y el art. 101 TFUE, puesto que ambos preceptos prohíben los acuerdos y las prácticas concertadas que puedan tener por objeto 
o efecto impedir, restringir o falsear el juego de la competencia dentro del mercado nacional o comunitario.

En su defensa, los imputados invocaron, junto con otros argumentos que nos interesan aquí menos, el principio de confianza legítima. En concreto alegaron que únicamente habían asistido a reuniones por orden e indicación de la autoridad portuaria de Barcelona y dentro sus foros u organismos y, a veces, incluso también de la Generalitat de Catalunya. Por el contrario, la APB asumió su responsabilidad y calificó de "error" en sus alegaciones el haber participado en la elaboración de los costes y en las reuniones en las que se trataban temas contrarios a la competencia, pero justificó su actuación por la importancia de evitar la conflictividad en el Puerto de Barcelona. Además, manifestó que, a la par de su errónea actuación, también llevó a cabo actuaciones que revelaban un distanciamiento público de las conductas anticompetitivas de ALTG y TRANSCONT (fue quien puso en conocimiento de la CNG la realización de prácticas anticompetitivas por ambas asociaciones de transportistas), por lo que solicitó su exculpación. Finalmente, para dejar clara la imposibilidad de su imputación, recordó que, dado su carácter de Administración Pública, no competía en el mercado de referencia ni obtenía beneficios económicos de la realización de conductas colusorias en el mismo. Es esta última alegación la más relevante a nuestros efectos.

Como respuesta a las anteriores alegaciones, la GNC concluyó que la actividad llevada a cabo por los operadores privados se había venido desarrollado bajo las directrices marcadas por el cartel operativo en el Puerto de Barcelona, lo que suponía una conducta prohibida por los artículos 1 de la LDC y 101 del TFUE que debía ser sancionada, sin posibilidad de amparo en el principio de confianza legítima por tratarse de un sector plenamente liberalizado.

Respecto a la $\mathrm{APB}$, la resolución de la CNC afirmó que su aparición "en la escena de acuerdos entre empresas en el momento en el que estaban siendo perseguidos por la autoridad de competencia, pudo fácilmente contribuir a una menor efectividad de su actuación sancionadora, dando además ocasión a interpretaciones oportunistas como las alegadas por los imputados, de ser acuerdos amparados por la Administración Pública". Consecuentemente, la autoridad de la competencia declaró a la APB facilitadora de la infracción cometida por los operadores privados, en la medida en que les permitió utilizar a un organismo público como coartada y revestir de lícito un acuerdo que de sobra sabían era anticompetitivo.

Por todo lo anterior, la GNC sancionó a CONTRAPORT (sucesora de TRANSCONT) y ALTC por infringir el art. 1 LDG y el art. 101 TFUE y a la APB por facilitar dicha infracción. En concreto, a ésta impuso multa de 100.000 euros. Poca cuantía en comparación con la que sufrieron otros responsables de la misma 
infracción (por ejemplo, a ALTG se le impuso multa algo superior a quince millones de euros). Pero, aun así, en este caso, la Administración no se libró de la multa, como sí sucedió con la CAP de la Junta de Andalucía. Y ello pese a que, cuando se cometieron las infracciones en el Puerto de Barcelona, la doctrina que permitía declarar la responsabilidad sancionadora de las Administraciones por actuar como poder público en contra de la competencia era casi tan desconocida e inaplicada como cuando la CAP auspició el cartel de los vinos de Jerez. Con independencia de si esa diferencia de trato estaba o no justificada, se pone de manifiesto que las autoridades de defensa de la competencia se proponen ya, no sólo declarar una responsabilidad teórica de las Administraciones cuando actúan como poder público, sino sancionarlas efectivamente.

\section{Sentencia de la Audiencia Nacional}

Contra tal resolución, la APB interpuso recurso contencioso-administrativo aduciendo el mismo motivo que el alegado ante la CNG: que su conducta no podía calificarse de anticompetitiva porque no competía en el mercado de referencia ni obtenía beneficios económicos de la realización de conductas colusorias en ese mercado. Tras ello solicitó su exculpación por no ser susceptible de sanción al haber actuado en el ejercicio de funciones públicas. En apoyo de su defensa sostuvo que, como autoridad administrativa, no podía ser responsable de una infracción de competencia porque tal y como define la Disposición Adicional Cuarta de la LDC, "cártel es todo acuerdo secreto entre dos o más competidores cuyo objeto sea la fijación de precios, de cuotas de producción o de venta, el reparto de mercados, incluidas las pujas fraudulentas, o la restricción de las importaciones o las exportaciones". Invocó también el art. 4 LDC, por haber realizado sus conductas al amparo de una Ley (la Ley 33/2010, de modificación de la Ley 48/2003, de régimen económico de prestación de servicios en los puertos de interés general y de la regulación del Real Decreto Legislativo 2/2011, por el que se aprueba el Texto Refundido de la Ley de Puertos del Estado y de la Marina Mercante) que le atribuye potestades de gestión y ordenación del sector.

En la resolución de dicho recurso, la SAN de 6 de febrero de 2017, recurso contencioso- administrativo no 51/2013, consideró que la APB admitió su participación y conocimiento de los acuerdos colusorios al calificar de error el haber participado en la elaboración de los costes y en reuniones en las que se trataban temas contrarios a la Defensa de la Competencia. Ello, junto con la existencia de varios documentos obrantes en el expediente administrativo, permitieron concluir que la recurrente sí participó en reuniones en las que se adoptaron acuerdos sobre la fijación de precios.

Sin embargo, a juicio de la Audiencia Nacional, lo verdaderamente dudoso y que procedía resolver era si la CNG podía declarar responsable a un órgano de 
una Administración Pública, como es la APB, por participar en un cártel cuando no ha actuado como operador económico sino en el ejercicio de funciones públicas. En definitiva, se trataba de determinar si la participación de la Administración en un acuerdo anticompetitivo como facilitadora, al margen de las prerrogativas que le otorga el ordenamiento jurídico y sin amparo legal ex art. 4 LDC, constituye una conducta que cae bajo el ámbito del art. 1 LDC. Es decir, se trataba de resolver la misma cuestión que se planteó a propósito del caso del cártel de los productores de vino de Jerez. Por ello, a pesar de su pronunciamiento anterior en otra dirección, en esta ocasión la Audiencia Nacional se remitió a la STS de 18 de julio de 2016 (caso del cartel de los productores de vino de Jerez), y, en consecuencia, falló la desestimación del recurso interpuesto por la Autoridad Portuaria de Barcelona y confirmó la sanción que le había impuesto la resolución de la GNC de 10 de enero de 2013.

No obstante, cuenta la sentencia con un voto particular del Magistrado Ilmo. Sr. D. Santiago Soldevila Fragoso que pone de nuevo de manifiesto la polémica existente. El Magistrado discrepante apoyó su postura en varios motivos: el Derecho europeo de la competencia tiene por objeto las actividades de las empresas; el TJUE ha declarado reiteradamente que debe calificarse como "empresa" cualquier entidad que ejerza una actividad económica, con independencia de la naturaleza jurídica de dicha entidad y de su modo de financiación; constituye una actividad económica cualquier actividad consistente en ofrecer bienes o servicios en un determinado mercado; $y$, conforme a la jurisprudencia del TJUE, las actividades vinculadas al ejercicio de prerrogativas de poder público no tienen carácter económico. Recordó el voto particular que esta doctrina, contraria a sancionar a una Administración Pública por excederse en el ejercicio de sus potestades, fue impulsada por la Comisión Europea desde un inicio. A su parecer, "un buen ejemplo de ello lo constituye la Decisión de 2 de abril de 2003 (Asunto COMP/C.38.279/ F3 -Carnes de vacuno francesas-). En la crisis de las vacas locas, el Ministro francés de Agricultura tuvo una destacada actuación de mediación y concertación entre los agentes económicos afectados. Tal y como se indica en el apartado 151 de dicha resolución, existen manifestaciones explícitas de su implicación en el acuerdo declarado anticompetitivo que firmaron los implicados. A pesar de ello, la Comisión no se dirigió contra del Estado francés, pues el acuerdo anticompetitivo se había suscrito entre partes privadas, limitándose el ministro a convocar las reuniones y fomentar el acuerdo. La razón de esta no imputación al ministro, según puede deducirse de la jurisprudencia citada, radica en el hecho de que la autoridad pública actuó en ese caso en el ejercicio de sus funciones propias de soberanía". De otra parte, añade este documentado, lúcido y sugerente voto particular, que incluso aunque se aceptara la posibilidad de sancionar a los "facilitadores" de infracciones de defensa de la competencia, eso sólo podrá aplicarse a empresas, no a Administraciones. Por todo eso, en suma, según el Magistrado 
disidente, aunque la APB participó en los acuerdos de fijación de precios llevados a cabo por los operadores económicos privados, lo hizo en calidad de Administración Pública reguladora del sector, por lo que su conducta, aunque ilícita, no puede ser sancionada conforme al art. 1 LDC: la APB "se extralimitó" pero "no puede ser sujeto de una infracción de Derecho de la competencia”.

Desconocemos si la APB ha recurrido en casación. Sí sabemos que lo hicieron tanto ALTC como CONTRAPORT, recursos ambos inadmitidos por falta de interés casacional objetivo (AATS de 10 de abril y de 18 de octubre de 2017, casaciones 227 y 3701/2017; JUR 2017/90480 y 258104). Si efectivamente la APB ha interpuesto casación hay motivos sobrados para su admisión pues no parece haber duda del interés casacional. Pero, por ahora, a la espera de la eventual sentencia del TS, hemos de conformarnos con los pronunciamientos de los que hemos dado cuenta.

\section{EL DEBATE DOGTRINAL}

Ya hemos visto cuán controvertida está resultando la solución de la cuestión abordada: frente a la postura de la CNG, la de la AN; y frente a la de ésta, la del TS. Ello, eventualmente, con rectificaciones y con votos particulares. Sólo falta que intervenga el TC, lo que no sería imposible porque al menos en parte puede estar en cuestión el respeto al art. $25 \mathrm{CE}$. Lo cierto y lo que ahora conviene añadir es que paralelamente a ese diálogo entre autoridades de defensa de la competencia y tribunales se ha desarrollado un interesante debate doctrinal.

Por una parte, Costas Comesaña y Hortalà i Vallvé defienden que las autoridades administrativas de defensa de la competencia sí que son competentes para "investigar (y sancionar) los efectos restrictivos de la competencia de una actuación de hecho de la Administración"5 porque lo relevante para aplicar o no la normativa de competencia no es la condición jurídica del sujeto, sino los posibles efectos de su conducta en el mercado. En suma, su posición coincide con la mantenida por la CNG en las dos resoluciones antes expuestas, con la del TS y con la finalmente acogida, quizá a regañadientes, por la AN.

Por otra parte, Marcos Fernández asume la tesis defendida en el voto particular de la consejera María Jesús González López y con la inicial de la AN, que sigue mantenido su Magistrado Soldevila. Ello por considerar que las autoridades de defensa de la competencia no pueden declarar una eventual infracción de la normativa de defensa de la competencia por parte de la Administración cuando ésta actúa como poder público. Eso es propio de la jurisdicción contencioso-administrativa: no

COSTAS GOMESAÑA, Julio y HORTALÀ I VALLVÉ, Joaquim, "La tipificación de la actividad de la Administración como facilitadora de cárteles", Anuario de la competencia, nº 1, 2013, pp. 13 y 19. 
es que a ésta corresponda sancionar a la Administración por su conducta contraria a la competencia, pero sí declarar que su conducta no es conforme a Derecho y, en su caso, anularla. Como consecuencia, afirma que lo que podría hacer la CNG (o, ahora, la CNMG) es impugnar ante la jurisdicción contencioso-administrativa los actos y disposiciones generales de las Administraciones Públicas de los que se deriven obstáculos al mantenimiento de una competencia efectiva en los mercados, impugnación posible por la legitimación que confería antes el art. 12.3 LDG y que otorga ahora el art. 5.4 LCNMC.

Completaremos los argumentos de una y otra corriente al abordar ahora los puntos o aspectos más destacables en que se puede descomponer el problema.

\section{LA ADMINISTRACIÓN Y SU INGIDENGIA EN EL MERGADO: COMO OPERADOR ECONÓMICO Y COMO PODER PÚBLICO}

A efectos de la legislación de defensa de la competencia lo tradicional es distinguir según la Administración actúe como un operador económico o en ejercicio de prerrogativas públicas. Tal vez, la clasificación sea excesivamente simplista; acaso en esa simplificación esté el germen de muchas dificultades; quizá es difícil encuadrar en esos dos géneros todas las situaciones. Por ejemplo, no es fácil adscribir sin matices a uno de esos dos grupos la actividad administrativa de servicio público o la que afronta cuando demanda para ella en el mercado bienes y servicios? ${ }^{7}$ Pero, como de-

6 MARCOS FERNÁNDEZ, Francisco, "El ámbito de aplicación subjetivo de la LDC y la conducta de la Junta de Andalucía en el cártel de la uva y del mosto de Jerez: Comentario a la RCNC de 6 de octubre de 2011, Exp. S/0167/09", Revista de Derecho de la Competencia y la Distribución, n 11, 2012, p. 26.

En estos casos se duda sobre la aplicación de la legislación de defensa de la competencia a la Administración Pública. Sin embargo, la jurisprudencia comunitaria, siguiendo la tendencia liberalizadora que viene caracterizando a la Unión Europea, busca someter a la normativa de competencia cualquier oferta o demanda de bienes o servicios en el mercado. Independientemente de quién provenga. Como consecuencia, ha ocurrido que organismos prestadores de servicios públicos han sido sancionados por autoridades de competencia europeas y españolas por realizar conductas anticompetitivas mientras se aprovisionaban de los productos necesarios para realizar su actividad prestacional. Las autoridades sancionadoras interpretaron que los organismos públicos, en sus relaciones con los beneficiarios de los servicios públicos que prestaban, quedaban excluidos del sometimiento a la legislación antitrust, pero no cuando actuaban en el mercado como cualquier otro operador económico, aprovisionándose de bienes o servicios para desempeñar su actividad. Sin embargo, ni toda la jurisprudencia ni la totalidad de la doctrina comparten este razonamiento. Buena parte de la jurisprudencia y doctrina considera que el carácter solidario del uso del producto adquirido se extiende a la actividad previa de aprovisionamiento, por lo que tampoco en esa fase los organismos públicos se encuentran sometidos a la legislación de defensa de la competencia. A este respecto, vid. MARCOS FERNÁNDEZ, Francisco, ¿Pueden las administraciones públicas infringir la ley de defensa de la competencia cuando adquieren bienes o contratan servicios en el mercado?, Actas de Derecho Industrial y Derecho de Autor, vol. 29, 2009, pp. 840-865. 
cimos, esa distinción bipartita es la habitual y la que late en las posturas enfrentadas que hemos ido viendo. Atengámonos, pues, a ella.

Cuando la Administración realiza una pura actividad empresarial en virtud de la iniciativa económica que ampliamente permite el art. 128 de la $\mathrm{CE}^{8}$ actúa como un operador económico más y se encuentra sometida a las mismas reglas de actuación que el resto de operadores privados; muy especialmente se encuentra sometida a la legislación de defensa de la competencia. Da igual que lo haga directamente una Administración territorial o que lo haga a través de alguno de sus entes instrumentales y, por supuesto, es irrelevante que estos tengan personalidad de Derecho público (los clásicos organismos autónomos o las entidades públicas empresariales o cualquiera de sus formas) o de Derecho privado (sociedades mercantiles de propiedad pública o fundaciones en mano pública). El Derecho de la competencia europeo y español ha adoptado un concepto amplio de empresa, entendiendo como tal "cualquier agente que realice una actividad económica en el mercado, con independencia de su forma legal o de su naturaleza pública o privada"9. Y en ese concepto amplio entran sin problemas todos los entes del sector público. En este punto no hay controversia y lo admiten por igual los valedores de las dos tesis expuestas ${ }^{10}$. Corolario de todo ello es que las autoridades de defensa de la competencia pueden sancionar a las Administraciones conforme a la LDC o a las previsiones del Derecho de la Unión Europea: aquí nunca se han planteado dudas sobre la posible responsabilidad sancionadora de las Administraciones, como sí se han planteado en otros sectores ${ }^{11}$, y, siendo así, cuando actúa como operador económico y realiza infracciones contra la competencia (pactos colusorios, abuso de posición dominante o actos de competencia desleal que falsean la libre competencia, conforme a los arts. 1 a 3 LCD) puede ser sancionada.

Por el contrario, cuando la Administración actúa en ejercicio de prerrogativas públicas -en ejercicio de su ius imperii, de funciones públicas, como poder público, según las expresiones que suelen emplearse- ya no es un operador económico ni es

8 MARCOS FERNÁNDEZ, Francisco, "Título I. De la defensa de la competencia”, Comentario a la ley de defensa de la competencia y a los preceptos sobre organización y procedimientos de la Ley de creación de la Comisión Nacional de los Mercados y la Competencia, coordinada por MASSAGUER FUENTES, Josep, $4^{\text {a }}$ Edición, Civitas, 2015, Madrid, p. 365.

9 ARRANZ FERNÁNDEZ-BRAVO, Tomás y MOSCOSO DEL PRADO GONZÁLEZ, Luis, "Desarrollo reciente de la aplicación de las normas de defensa de la competencia a las Administraciones Públicas", Actualidad Jurídica Uría Menéndez, no 32, 2012, p. 86.

10 COSTAS COMESAÑA, Julio, "La sujeción de la actividad de la Administración al Derecho de la competencia", Estudios de derecho mercantil: Libro homenaje al Prof. Dr. Dr.h.c. Fosé Antonio Gómez Segade, coordinada por TOBÍO RIBAS, Ana María, Marcial Pons, 2013, Madrid, p. 372; y MARCOS FERNÁNDEZ, Francisco (2015): 365.

11 Vid. VERAJURADO, Diego, "Las sanciones entre Administraciones Públicas", Fusticia Administrativa, número extraordinario, 2001, pp. 53-74. 
equiparable a un agente privado. Ya no realiza una actividad económica, ya no es empresa, ni siquiera acogiendo los conceptos amplios que de ello adopta el Derecho de la competencia. Y, como no realiza una actividad económica ni es empresa, no puede propiamente realizar las infracciones contra la competencia. Así, según el planteamiento tradicional, no puede ser responsable de tales infracciones, no por ningún privilegio personal ni nada similar, sino por una especie de imposibilidad de realizar las acciones tipificadas como infracciones de la competencia. No es responsable de esas infracciones sencillamente porque, al no ser ni actuar como empresa, no puede cometerlas.

Ahora bien, esa postura, que recoge lo que hasta ahora se aceptaba, no niega la posibilidad de que la Administración actuando como poder público realice actos restrictivos de la competencia. Actos que algunas veces pueden ser legales -en cuyo caso supondrán restricciones a la competencia queridas o admitidas resignadamente por el ordenamiento en favor de otros intereses generales prevalentes- pero que también podrían ser ilegales. Ilegales precisamente por restringir indebidamente la competencia, ya sea en favor de las empresas de la propia Administración ya sea en favor de terceros, esto es, de una o algunas empresas privadas. Porque, desde luego, como tiene declarado el Tribunal Supremo, incluso en el ejercicio de sus funciones públicas, la Administración está sometida a la $\mathrm{LDC}^{12}$.

El problema surge respecto a esta última hipótesis, es decir, respecto a las actuaciones de la Administración como poder público ilegales por contrarias a la legislación de competencia ¿Cómo se combaten? Es aquí donde las resoluciones y sentencias analizadas dan un salto respecto a la situación anterior: hasta ahora había ciertos mecanismos para reaccionar frente a esos comportamientos administrativos contra la competencia, pero no posibilidad de sanciones, ciertos mecanismos que de inmediato recordaremos; ahora se admite también que las autoridades de defensa de la competencia sancionen a la Administración incluso cuando actúa como poder público si no respeta las reglas de la competencia y para ello introduce otras novedades asimismo cuestionables, como la figura del facilitador. Pero sigamos paso a paso.

\section{LA ADMINISTRAGIÓN Y LAS GONDUGTAS EXENTAS POR LEY}

Hace un momento hemos hablado de actuaciones administrativas restrictivas de la competencia legales e ilegales. De actuaciones legales e ilegales de la Administración cuando actúa como poder público. De actuaciones legales e ilegales desde la 
perspectiva de la legislación de defensa de la competencia Es esa distinción la que fundamentalmente refleja el art. 4 LDC bajo el rubro "Conductas exentas por ley".

En virtud de su apartado 1, cualquier ley -no un reglamento- puede admitir conductas que, en principio, son contrarias a la propia LDG o, en general, a las reglas sobre la libre competencia. Ello salvo que sea contrario al Derecho europeo. Pero, prescindiendo de este matiz, que no importa para lo que aquí nos incumbe, el precepto significa que cualquier norma con rango de ley, sea estatal o autonómica, puede convertir en lícita una conducta en principio prohibida por la LDC. Naturalmente, si eso sucede, tampoco cabrá sancionar la conducta como si fuera una de las infracciones de la LDC. La conducta dejará de ser antijurídica y, por tanto, aunque siga siendo típica conforme a la LDC, no cabrá ni sancionarla ni acordar su cese ni ninguna otra medida contra ella ni contra su autor. Aunque este art. 4.1 LDC no nombra expresamente a la Administración, se proyecta sobre ella y su comportamiento. Porque en tanto que esas leyes otorguen potestades a la Administración que comporten la restricción de la competencia supondrán que las actuaciones administrativas fruto del ejercicio de esas potestades serán lícitas. Es enorme el campo que cubre este art. 4.1 LDC. Infinidad de reglamentos y actos administrativos restringen la competencia, pero lo hacen amparados por una ley y, en tal caso, nada cabe objetar a esos reglamentos y actos administrativos.

El art. 4.2 LDC ofrece la otra cara de la misma moneda, que es la que aquí nos importa. Cuando las Administraciones restrinjan la competencia, esto es, vulneren las reglas de la propia LDC, sin dicho amparo legal, la LDC debe aplicarse. Da igual que formalmente se presenten como ejercicio de otras potestades administrativas o sean causadas por la actuación de los poderes públicos o las empresas públicas. Da igual que beneficien a la propia Administración o a sus empresas o que favorezcan a ciertas empresas privadas. Nada de eso importa. En cualquier caso, la actuación administrativa que haya propiciado esa restricción de la competencia será ilegal; e ilegal será igualmente el comportamiento de las empresas (privadas o públicas) que se basen en esa actuación administrativa.

Desde este punto de vista, los comportamientos de la CAP y de la APB encajan en el art. 4.2 LDC: auspiciaban dos cárteles sin contar con ningún amparo legal. Se trataba de actuaciones frontalmente contrarias a las normas de defensa de la competencia. Si acaso cabría decir que la CAP y la APB actuaban dentro del ámbito de sus competencias; pero entonces hay que añadir de inmediato que ejercían ilegalmente sus competencias Acaso, cabría también decir que ejercían potestades atribuidas por el ordenamiento; pero de inmediato habría que añadir que ejercían esas potestades con flagrante ilegalidad. Así que, en cualquier caso, habían actuado ilegalmente. Pero con esa conclusión irrebatible no se resuelve el problema. Sólo queda planteado. 
Porque, a partir de esa incontrovertida ilegalidad, las dudas que se abren son otras: ¿se podrá sancionar a las empresas privadas que han incurrido en violación de la LDG como si la Administración no hubiera intervenido?; y, sobre todo, que es lo que aquí importa, ¿cómo se combate la actuación administrativa ilegal? De nuevo, es respecto a esto último donde las resoluciones y sentencias analizadas introducen una novedad de bulto: consideran que los medios tradicionales de combatir ese comportamiento anticompetitivo de la Administración cuando actúa como poder público son insuficientes e ineficaces; y, como alternativa, construyen otra vía que consiste sin más en sancionar a la Administración; sancionarla aunque no es ni está actuando como empresa, aunque no está realizando actividad económica sino actuando como poder público; sancionarla aunque propiamente no ha realizado ni podido realizar la conducta típica sino que la ha facilitado. Pero, ¿cuáles son los otros remedios?, ¿`son realmente ineficaces?

\section{LA LEGITIMACIÓN DE LAS AUTORIDADES DE DEFENSA DE LA COMPETENCIA PARA IMPUGNAR ACTUACIONES ADMI- NISTRATIVAS GONTRARIAS A LA COMPETENCIA}

Hasta la vigente LDC de 2007 no había ningún cauce ad hoc para atacar las acciones administrativas contrarias a la defensa de la competencia, aunque no cabe descartar que los generales previstos en la LJCA permitieran a los sujetos legitimados (destacadamente, los empresarios que se sintieran perjudicados) impugnar esas actuaciones: las vulneraciones de la LDC, como las de cualquier ley, son vulneraciones del ordenamiento jurídico y, como tales, determinan la invalidez (nulidad o anulabilidad) de los reglamentos y actos administrativos que los vulneren. La sentencia estimatoria podría reducirse a declarar la ilegalidad de la actuación administrativa, pero también podría anularla y ordenar todas las medidas necesarias para el pleno restablecimiento de la legalidad (art. 71 LJCA). Incluso podrían eventualmente los sujetos privados legitimados utilizar el recurso contencioso-administrativo contra la vía de hecho (art. 30 LJCA) si la actuación administrativa contraria a la LDC adoptara esa forma, supuesto en el que la sentencia estimatoria, además de declarar la ilegalidad, podría ordenar el cese de la actuación administrativa, como se desprende del art. 32.2 LJCA. Pero lo que desde luego no había era ninguna posibilidad de que los órganos de defensa de la competencia impugnaran ante la jurisdicción contencioso-administrativa las actuaciones de la Administración que considerasen contrarias a la LDC: sencillamente no tenían legitimación para hacerlo porque no la tenían conforme a las reglas generales (evidentemente no tienen ningún derecho subjetivo ni un interés legítimo afectado) y porque no había ninguna regla especial que se la reconociera. 
Justamente para solventar esa carencia, la LDC de 2007 incluyó esto en su art. 12.3:

"La Comisión Nacional de la Competencia está legitimada para impugnar ante la jurisdicción competente actos de las Administraciones Públicas sujetos al Derecho Administrativo y disposiciones generales de rango inferior a la ley de los que se deriven obstáculos al mantenimiento de una competencia efectiva en los mercados".

En la actualidad hay que estar a lo dispuesto en el art. 5.4 LCNMC, que establece:

"En cumplimiento de sus funciones, la Comisión Nacional de los Mercados y la Competencia está legitimada para impugnar ante la jurisdicción competente los actos de las Administraciones Públicas sujetos al Derecho administrativo y disposiciones generales de rango inferior a la ley de los que se deriven obstáculos al mantenimiento de una competencia efectiva en los mercados".

Ante ello, cabría pensar que el problema que nos ha traído hasta aquí quedó zanjado: lo que habría procedido en los dos casos analizados sería que la GNC hubiese recurrido la actuación de la CAP y la de la APB conforme a aquel art. 12.3. Las cosas, sin embargo, son más complicadas por varias razones.

Primero, porque en los dos casos de la CAP y de la APB no había ni reglamentos ni actos administrativos que impugnar. Es algo en lo que se apoya el Tribunal Supremo para declarar la responsabilidad sancionadora de la Administración como facilitadora ${ }^{13} \mathrm{y}$ en lo que coinciden sus comentaristas, tanto los que defienden la competencia de la GNC, actual GNMC, para sancionar a la Administración, como los que alegan que la única vía posible para atacar las actuaciones administrativas contrarias a la competencia es su impugnación ante la jurisdicción contencioso-administrativa $^{14}$. Eran actuaciones administrativas informales y casi meramente materiales

13 Vid. STS de 18 de julio de 2016, recurso de casación n ${ }^{\circ}$ 2946/2013, fundamento jurídico 4 (caso del cartel de los productores de vino de Jerez): "no siempre resulta sencillo determinar si una Administración está actuando, o no, en el ejercicio de potestades públicas. Sobre todo, si, como sucede en el caso que examinamos, su actuación no se exterioriza en actos formales, realizados a través del procedimiento establecido en las normas, sino que se plasma en actuaciones materiales, más o menos difusas, cuya impugnación en vía jurisdiccional conforme a lo previsto en el citado artículo 12.3 de la Ley 15/2007 resultaría escasamente viable".

14 Los autores que defienden que la autoridad de la competencia es competente para investigar los efectos restrictivos de la competencia de una actuación administrativa, lo hacen apoyándose precisamente en que la vía del art. 12.3 LDC no es accesible en estos casos por no existir verdaderos actos administrativos ni disposiciones generales emanados de la Administración, sino meramente actuaciones materiales deriva- 
las que contribuyeron decisivamente a la formación y desarrollo de los cárteles y, ante ello, ¿cómo articular un recurso contencioso-administrativo? Precisamente el no encontrar una respuesta satisfactoria ha sido determinante para que la CNC, los tribunales y parte de la doctrina opten por permitir sancionar sin más a la Administración.

Segundo, porque tanto el art. 12.3 LDC como el actual art. 5.4 LCNMC sólo hablan de legitimación para impugnar "actos (...) sujetos a Derecho Administrativo y disposiciones generales de rango inferior a la ley"; esto es, actos administrativos y reglamentos. Nada se dice sobre los recursos contra actuaciones materiales. Así, aunque se admitiera que cabe el recurso contencioso-administrativo contra la vía de hecho del art. 30 LJCA por actuaciones administrativas materiales que vulneren la competencia, se chocaría con una dificultad adicional: ¿la legitimación de las autoridades de defensa de la competencia incluye la posibilidad de recursos frente a la vía de hecho pese a la literalidad de los arts. 12.3 LDG y 5.4 LCNMG? ${ }^{15}$.

das de la misma. A este respecto, vid. COSTAS COMESAÑA, Julio y HORTALÀ I VALLVÉ, Joaquim (2013): 30 y 31 .

Del mismo modo, la corriente que aboga por la incompetencia de la CNC para declarar la responsabilidad de la Administración Pública por infringir normas de Derecho de la competencia, reconoce que la vía de la jurisdicción contenciosa-administrativa, del vigente art. 5.4 LCNMC, resulta de escasa utilidad para casos como este, en el que la Administración no dicta actos administrativos ni disposiciones generales, sino que actúa sin dejar ningún rastro formal que se pueda impugnar ante los tribunales. En relación con ello, vid. MARCOS FERNÁNDEZ, Francisco (2012): 26 y 27; y MARCOS FERNÁNDEZ, Francisco, "¿Puede sancionarse a las Administraciones Públicas cuando no actúan como operador económico si restringen la competencia o promueven conductas anticompetitivas?, InDret, 2018, pp. 17 y 18.

15 Según la consejera Doña María Jesús González López -que, como ya he destacado anteriormente, emitió voto particular a la resolución de la CNC de 6 de octubre de 2011 por entender que la extralimitación de una Administración Pública en el ejercicio de sus potestades no implica automáticamente que actúe como operador económico y que pueda ser sancionada por las autoridades de la competencia- si el legislador hubiera querido que las Administraciones Públicas estuvieran estrictamente sujetas a la LDC en el ejercicio de sus potestades de imperium no habría introducido un precepto tan medido como el art. 12.3 LDC, o posterior art. 5.4 LCNMC. Por lo que, a su parecer, ni siquiera cabe el recurso contra la vía de hecho. Sin embargo, no toda la doctrina coincide en esta apreciación. GuillÉn GARAMÉs considera que la CNC sí que es competente para interponer el recurso contra la vía de hecho del art. 30 LJCA porque el art. 26 LDC, apartado e), le legitima para establecer las medidas necesarias para el restablecimiento de la competencia en los mercados. Para este autor, no hay que entender el art. 12.3 LDC, actual art. 5.4 LCN$\mathrm{MC}$, en términos restrictivos, sino que se debe interpretar teniendo en cuenta la potestad de la CNC para promover la competencia (advocacy) y el mencionado precepto de la LJCA, en el sentido de que no se puede restringir la legitimación de la CNC, actual CNMC, a la impugnación de actos administrativos y reglamentos, sino que debe extenderse al resto de actividad administrativa impugnable ante la jurisdicción contencioso-administrativa, como es la inactividad de la Administración que constituye vía de hecho, siempre que de la misma se deriven obstáculos al mantenimiento de una competencia efectiva en los mercados. En este sentido, vid. GUILLÉN CARAMÉS, Javier, "La promoción de la competencia como refuerzo al ejercicio de la potestad sancionadora por parte de las autoridades de competencia: en especial, la impugnación de la actividad administrativa contraria al Derecho de la competencia", Cuestiones actuales del procedimiento san- 
Tercero, porque esos dos artículos se refieren precisamente a la GNG y ahora a la GNMC. ¿Es que los órganos autonómicos de defensa de la competencia no tienen esa legitimación? Si la respuesta fuese negativa estaría claro que para esos órganos autonómicos no habría ninguna solución salvo la de sancionar a la Administración. Pero lo cierto es que la Ley 1/2002, de 21 de febrero, de coordinación de las competencias del Estado y las Comunidades Autónomas en materia de Defensa de la Competencia, determina en su art. 1 que tanto el Estado como las Comunidades Autónomas pueden ejercer las competencias reconocidas en la LDC en relación con las conductas previstas en los artículos 1, 6 y 7 de la misma, determinándose el competente en cada caso concreto según el ámbito territorial en el que las conductas anticompetitivas tengan efectos: si los efectos se circunscriben al territorio de una Comunidad Autónoma, será la autoridad autonómica de competencia de esa región la encargada de ejercer las competencias de que se traten; pero si los efectos de la conducta anticompetitivas trascienden al conjunto del mercado nacional, entonces será la CNMG la encargada de realizar las actuaciones correspondientes ${ }^{16}$. De ello se deduce que la legitimación atribuida por el art. 5.4 LCNMC a la CNMC también se entiende atribuida a las autoridades autonómicas de competencia cuando los efectos de la conducta colusoria impugnada se reducen al ámbito de una Comunidad Autónoma ${ }^{17}$, por lo que estas autoridades de competencia no se verían obligadas a sancionar a la Administración, sino que podrían encontrar este cauce alternativo para resolver la cuestión. Como consecuencia, esta tercera observación no constituye un verdadero inconveniente.

Cuarto, porque, aunque se superen todos los demás problemas anteriores, el recurso contra la actividad material de la Administración está configurado en el art. 30 LJCA como un cauce estrecho. Su misma alusión a la vía de hecho hace pensar que lo que por este cauce cabe atacar con éxito no es cualquier actividad material ilícita sino sólo aquéllas grosera y manifiestamente ilegales; según la concepción tradicional de la vía de hecho, sólo entrarían en ella aquellas actuaciones administra-

cionador en Derecho de la competencia, dirigida por GUILLÉN CARAMÉS, Javier, Civitas, 2013, Cizur Menor (Navarra), pp.389-391.

${ }_{16}$ Vid. GUILLÉN CARAMÉS, Javier, "Las competencias de la Comisión Nacional de los Mercados y de la Competencia y las autoridades autonómicas en la aplicación del Derecho de la competencia", Estudios de Deusto, vol. 63, nº 1, 2015, pp. 37-83.

17 A este respecto, Marcos Fernández afirma que las autoridades autonómicas son las competentes para instruir y resolver los procedimientos sancionadores sobre las conductas prohibidas por los artículos 1, 2 y 3 de la LDC que distorsionen la competencia en el ámbito autonómico. En MARCOS FERNÁNDEZ, Francisco, "Competencias autonómicas en los procesos de concentración de empresas", InDret, n 4, 2011, pp. 1-53. 
tivas con incompetencia palmaria o con total falta de procedimiento ${ }^{18}$. Aplicando esas ideas a los casos de los que aquí partimos, cabe decir que habría sido muy difícil articular un recurso contra los comportamientos de la CAP y de la APB; y poco probable que tales recursos hubieran prosperado. Probablemente el recurso contra la vía de hecho debería reformarse para convertirlo en una vía más amplia y efectiva; aún más probablemente, incluso sin reforma legal, los jueces deberían acogerlo con más amplitud de lo que lo vienen haciendo. Pero, prescindiendo de todo ello, lo cierto es que, aunque se admita que las autoridades de defensa de la competencia puedan interponer recursos contra vías de hecho administrativas anticompetitivas, encontrarían muchos escollos para luchar por esta vía contra comportamientos como los de la CAP y la APB.

Y, quinto, porque esos artículos no niegan por sí mismos la posibilidad de sancionar a la Administración por sus actuaciones contrarias a la LDC. Es verdad que, al menos para algunos casos, ofrecen una vía. Pero, incluso cuando esa vía sea transitable, no es nada seguro que se deduzca de ellos que no quepa, además, sancionar a la Administración, como parecen haber entendido algunas de las resoluciones y sentencias reseñadas, así como sus comentaristas. Parece latir en sus posturas la idea de que, si existen estos preceptos que dan legitimación a las autoridades de la competencia para impugnar ante la jurisdicción contencioso-administrativa, es que ésa es la única posibilidad que tienen; o sea, que esos preceptos están implícitamente negándoles la posibilidad de sancionar. Pero no tiene que ser así. Pensemos en el supuesto más simple y claro: el de los actos administrativos ilegales por contrarios a la LDC. Cabe sostener que las autoridades de defensa de la competencia pueden, de un lado, impugnar ante la jurisdicción contencioso-administrativa el acto, pero que pueden, de otro lado, sancionar a la Administración de la que emanó. No serían posibilidades alternativas y excluyentes sino acumulativas ${ }^{19}$. Y, dentro de esta interpretación,

18 Vid. LÓPEZ MENUDO, Francisco, "Título III. Objeto del Recurso Contencioso Administrativo. Capítulo Primero. Actividad administrativa impugnable", Revista española de derecho administrativo, $\mathrm{n}^{\circ} 100$, 1998, pp. 314-324. Véase también GONZÁLEZ PÉREZ, Jesús, Comentarios a la Ley de la jurisdicción contencioso-administrativa, Civitas, 2016, Cizur Menor (Navarra), pp. 434-446.

19 Coinciden con esta opinión algunos autores, como Costas Comesaña y Hortalà i Vallvé, que afirman que la vía del art. 5.4 LCNMC (impugnar la actividad administrativa perjudicial de la competencia ante la jurisdicción contencioso-administrativa) y la del art. 1 LDC (sancionar a la Administración que con su conducta limita la libertad de competencia) se podrían considerar vías diferentes y, por tanto, compatibles y respetuosas del non bis in idem, ya que ambas normas responden a una finalidad distinta. Mientras que la primera busca eliminar del ordenamiento jurídico actos o disposiciones administrativas contrarias a la Ley, la segunda se limita a perseguir actuaciones anticompetitivas, imponiendo en su caso la correspondiente sanción. A este respecto, vid. COSTAS COMESAÑA, Julio y HORTALÀ I VALLVÉ, Joaquim (2013): 30.

Del mismo modo opina BAÑo León, que considera que las Administraciones Públicas pueden ser sujetos pasivos de Derecho de la Competencia y, por tanto, ser sancionadas por la Comisión Nacional de la Competencia cuando realicen conductas administrativas constitutivas de ilícitos antitrust, independiente- 
caben a su vez, dos posibilidades. Una primera mantendría que las autoridades de la competencia podrían desde el principio usar una u otra vía o las dos, una para conseguir la anulación, otra para castigar la conducta. Y otra segunda interpretación consistiría en entender que las autoridades de la competencia deben empezar por recurrir el acto administrativo contrario a la LDC y, una vez que hayan conseguido su anulación, y sólo entonces, podrán además sancionar a la Administración que lo produjo. Se basaría esta interpretación en la idea de que cualquier acto administrativo tiene una presunción de validez que se impone a todas las autoridades administrativas, incluidas las de competencia, y que sólo destruida esa presunción de validez por la sentencia contencioso-administrativa cabrá que esas autoridades sancionen ${ }^{20}$. Sólo así se entiende la rigidez de los arts. 12.3 LDG y 5.4 LGNMC, que no aluden a la actividad material de la Administración por no contar esta con la presunción de validez con que sí cuentan los actos administrativos y reglamentos ${ }^{21}$. Sea como fuere,

mente de la vía que deja abierta el art. 5.4 LCNMC para que la CNMC impugne determinados actos de la Administración Pública ante la jurisdicción contencioso-administrativa. Véase BAÑO LEÓN, José María, "Libre competencia y Administración Pública: Derecho Administrativo y Derecho «antitrust»", Derecho de la regulación económica, Tomo IX. Comercio interior, dirigida por REBOLLO PUIG, Manuel, Iustel, 2013, Madrid, pp. 1205-1206.

20 La mejor expresión de esta segunda interpretación la ofrece NiETO, pues a su parecer, mientras no se produzca la declaración de invalidez, los actos administrativos son válidos por muy graves que sean sus vicios. Apud REBOLLO PUIG, Manuel, "La presunción de validez", Revista española de derecho administrativo, $n^{\circ} 128,2005$, p. 590. También Rebollo Puig sostiene en ese trabajo suyo que los actos administrativos son válidos en tanto no se declare su nulidad o sean anulados. Conforme a la presunción de validez de los actos administrativos defendida por estos autores, la Administración no podría ser sancionada por realizar un acto viciado hasta que este no se haya anulado o declarado nulo, pues sólo entonces aquella presunción será destruida. Vid. también en esta línea, REBOLLO PUIG, Manuel, "Reglamentos y actos administrativos ante el Tribunal de Defensa de la Competencia", Estudios de derecho público económico: libro homenaje al Prof. Dr. D. Sebastián Martin-Retortillo, coordinada por COSCULLUELA MONTANER, Luis, Civitas, 2003, Madrid, pp. 719-742, donde se recuerdan los obstáculos que encontraba el extinto Tribunal de Defensa de la Competencia para sancionar las conductas anticompetitivas de la Administración que encontraban fundamento en un acto administrativo o en un reglamento, precisamente por la virtualidad de la presunción de validez, pues conforme a ella hay que presumir, en tanto no se destruya la presunción, que la Administración ha actuado conforme a Derecho. Pone así Rebollo Puig de manifiesto el principal problema que puede encontrar el órgano administrativo encargado, en cada momento, de perseguir las conductas contrarias a la competencia. Para solucionarlo, la LDC atribuyó, en su art. 12.3, legitimación a la CNC para impugnar los actos administrativos y reglamentos contrarios a la competencia ante la jurisdicción contencioso-administrativa (competencia que mantiene el actual art. 5.4 LCNMC). Se solventa así el problema pues, en primer lugar, la autoridad de competencia podría impugnar el acto o reglamento ante la jurisdicción contencioso-administrativa, y una vez destruida la presunción de validez, proceder a sancionar la concreta conducta anticompetitiva amparada por el acto o reglamento.

${ }_{21}$ Además de este motivo, otros autores señalan que la vía del art. 5.4 LCNMC no está prevista para la actividad material de la Administración contraria a la competencia porque en estos casos no es tan importante anular jurídicamente la actuación como evitar que materialmente se sigan produciendo sus efectos, de modo que lo importante es que cese la actividad administrativa (lo que se puede conseguir a través de las sanciones impuestas por las autoridades de competencia) y que, en su caso, los sujetos damnifica- 
lo que quiere decirse es que del reconocimiento de legitimación a las autoridades de la competencia para interponer recursos frente a las actuaciones administrativas anticoncurrenciales no se desprende ninguna solución definitiva sobre la posibilidad o imposibilidad de que, además -antes, simultáneamente o después- impongan sanciones.

\section{LA RESPONSABILIDAD DE LAS ADMINISTRACIONES EN CONGEPTO DE "FAGILITADOR" DE INFRAGGIONES GON- TRA LA COMPETENCIA}

Hay un último elemento en las resoluciones de la GNC que sancionaron a la CAP y a la APB, así como en las sentencias confirmatorias y en la doctrina que las sustenta. En casi todas ellas, explícita o implícitamente, ocupa un papel fundamental la noción de "facilitador" de las infracciones: aceptan que, precisamente porque ni la CAP ni la APB actuaban como operadores en el mercado ni realizaban actividades económicas ni, por ende, eran empresas, no pudieron realizar propiamente la acción tipificada como infracción; pero manifiestan que sí que colaboraron activamente en los cárteles, propiciaron su formación y contribuyeron a su mantenimiento y efectividad real. Así que se las sanciona, no propiamente como autoras, sino como "facilitadoras" de las infracciones. O sea, se considera a la CAP y a la APB responsables de las infracciones de las que son autores otros sujetos, se les considera responsables a títulos de "facilitador". Pero, ¿de dónde viene ese concepto y qué supuestos cubre?, ¿se puede extender a la Administración?, ¿su utilización encuentra apoyo en la legislación española de defensa de la competencia?, ¿es conforme con las exigencias constitucionales? Trataré ahora de dar respuesta a estos interrogantes.

\section{La formación del concepto de facilitador en la jurisprudencia europea}

El origen de la figura del facilitador trae causa de que en la práctica se venía observando que no sólo eran causantes de las infracciones los autores de las mismas, sino también quienes las facilitaban, pues sin ellos se hacía mucho más difícil su comisión. Así se fue gestando una sensación de impunidad para con los sujetos que coadyuvaban a la realización de prácticas anticompetititvas, pero que no eran parte principal en las mismas. Eso fue haciendo crecer la preocupación de la Unión Europea.

dos se resarzan por la vía de la responsabilidad patrimonial. En este sentido, vid. ORTEGA BERNARDO, Julia, “'Se puede sancionar a la Administración en el ámbito de la Defensa de la Competencia?”, Almacén de Derecho, 31 de enero de 2017, recuperado de http://almacendederecho.org/ 
Fue con el caso Treuhand cuando la Comisión de las Comunidades Europeas empezó a aludir a la figura del facilitador de infracciones. Aunque a priori parecía ser una apreciación más de entre las relativas a los sujetos responsables, en realidad se trataba de un cambio de criterio que marcaría el camino a seguir por las autoridades europeas, y no sólo por ellas. En los expedientes anteriores, los sujetos sancionados por infringir el art. 101 TFUE, y demás normativa de defensa de la competencia, eran empresas competidoras, empresas que infringían la competencia porque realizaban prácticas anticompetitivas junto con otras empresas que operaban en el mismo mercado, y que, por tanto, mermaban su propia libertad de competencia y la del mercado en el que operaban. Sin embargo, en el expediente relativo a la sociedad AC-Treuhand, se sancionaba, junto a otros operadores económicos privados, a una sociedad asesora que nada tenía que ver con el mercado de referencia. Según De Stefano, la importancia de este cambio de criterio radica en que abre la puerta a sancionar, no sólo a las empresas competidoras que llevan a cabo una conducta anticompetitiva, sino a cualquier tipo de intermediario (market research organisations, trade associations, online platforms, as well as brokers, dealers, and other trading intermediaries) que, aunque no limita su propia competencia, con su actuación facilita que otras empresas se coordinen para alcanzar objetivos anticoncurrenciales ${ }^{22}$. Se pretende así perseguir un nuevo modelo de cartel que expande las fronteras de las conductas colusorias perseguidas hasta entonces por las leyes de competencia: the hub-and-spoke collusion, donde varias empresas competidoras cooperan bajo el mando de una empresa líder que no forma parte del mismo mercado que aquellas.

Cuando el asunto Treuhand llegó al TJUE, este Tribunal, movido por la preocupación de perseguir este tipo de conductas auxiliares, quiso dejar claros los requisitos esenciales que deben concurrir para poder apreciar la existencia de la figura del facilitador en su sentencia de 22 de octubre de 2015. Tales requisitos son los siguientes:

- Ejercer un papel esencial en la comisión de la infracción ${ }^{23}$ : en el caso de prácticas anticompetitivas, basta con organizar reuniones y participar activamente en ellas -incluso actuando como moderador e instando a la llegada de acuerdos-, facilitar datos e información a los operadores económicos que llevan a cabo la acción típica, contribuir a los objetivos comunes perseguidos por el conjunto de los participantes y tener conocimiento de los comportamientos materiales ejecutados por otras empresas en la

22 DE STEFANO, Gianni, "AC-Treuhand Judgment: a broader scope for EU competition law infringements?", Journal of European Competition Law Eं Practice, vol.6, n 10, 2015, p. 689.

23 A propósito del papel esencial de la entidad AC-Treuhand en el cártel de los proveedores de aditivos plásticos vid. S.H. CHAN, Sunny, "AC-Treuhand: What is the ambit of cartel facilitators' liability?", European Competition Law Review, Issue 4, 2016, Thomson Reuters, p. 133. 
consecución de dichos objetivos o poder preverlos y estar dispuesto a asumir el riesgo.

- No es necesario que -el facilitador- esté presente en los mercados afectados por las infracciones: AC-Treuhand era una sociedad privada asesora y, por tanto, no estaba presente en los mercados afectados por las prácticas anticompetitivas que facilitó, pero ello no impidió que el TJUE la declarara responsable de las mismas pues materialmente su conducta tuvo efectos negativos sobre esos mercados afectados ${ }^{24}$. Según el TJUE, ya no puede entenderse que el art. 101 TFUE se dirija únicamente a empresas, sino también a todas aquellas organizaciones que, aunque ajenas al mercado de referencia, faciliten la implantación de un cartel. Como ponen de manifiesto VAlLery y Schell, para formular esta idea, el TJUE no tuvo en cuenta la opinión del Abogado General Wahl emitida en sus conclusiones presentadas el 21 de mayo de 2015, basada en que no se puede sancionar en virtud del art. 101 TFUE a aquellas organizaciones que no formen parte del mercado afectado por el cartel porque el ámbito ratione personae de la prohibición de tal precepto se limita a las empresas que coluden con otras para reducir su competencia y la del mercado en que actúan en beneficio propio ${ }^{25}$.

- Que la sanción sea razonablemente previsible en el momento en que se cometieron las infracciones: este requisito, estrechamente ligado al principio de legalidad y de tipicidad, exige que el justiciable pueda saber, a partir del texto de la disposición pertinente, y si fuera necesario, con la ayuda de la interpretación de los tribunales, qué actos y omisiones son capaces de generar su responsabilidad. Sin embargo, estos principios de legalidad y tipicidad se flexibilizan en el Derecho sancionador de la UE. Según el TJUE, la sociedad AC-Treuhand "debería haber previsto, después de haber recurrido, en su caso, a un asesoramiento jurídico adecuado, que su comportamiento pudiera ser declarado incompatible con las normas de competencia del Derecho de la Unión, teniendo en cuenta especialmente el amplio alcance de los conceptos de «acuerdo» y de «práctica concertada» que resulta de la jurisprudencia del Tribunal de Justicia”.

24 Aunque la sociedad AC-Treuhand alegó que para ser responsable de una infracción del art. 101 TFUE es necesario tener algún tipo de relación con el mercado afectado por la restricción de la competencia, el TJUE concluyó que no era necesario tal posicionamiento en el mercado, pues es suficiente con que se tenga intención de contribuir y, de hecho, se contribuya, a los objetivos comunes perseguidos por los participantes en el acuerdo anticompetitivo. A este respecto, vid. S.H. CHAN, Sunny (2016): 133 y 134.

25 VALLERY, Anne y SCHELL, Caroline, "AC-Treuhand: Substantial Fines for Facilitators of Cartels", Fournal of European Competition Law \& Practice, vol. 7, nº 4, 2016, pp. 254 y 255. 
El TJUE ha seguido pronunciándose del mismo modo en posteriores sentencias, como es el caso de la STJUE de 21 de enero de 2016 (asunto ETURAS y otros) ${ }^{26}$. En este supuesto concreto, el TJUE recordó que "los modos pasivos de participación en la infracción, como la presencia de una empresa en reuniones en las que se concluyen acuerdos con un objeto contrario a la competencia, sin oponerse expresamente a ellos, reflejan una complicidad que puede conllevar su responsabilidad en virtud del artículo 101 TFUE, ya que la aprobación tácita de una iniciativa ilícita sin distanciarse públicamente de su contenido o denunciarla a las autoridades administrativas produce el efecto de incitar a que se continúe con la infracción y dificulta que se descubra". Parece asentarse la doctrina del facilitador de infracciones de competencia.

En cualquier caso, puede concluirse que esta figura -del facilitador de infracciones-, tal y como la ha configurado la jurisprudencia europea, puede subsumirse en el concepto de cómplice. Y como tal, su aplicación en el Derecho español requiere una serie de requisitos, muchos de los cuales se han incumplido en los casos de la CAP y de la APB. A ello dedicaremos los siguientes epígrafes.

\section{Posibles objeciones a la recepción de la responsabilidad por facilitar infracciones contra la competencia en el Derecho español}

Aunque la finalidad perseguida con la utilización de la figura del facilitador sea loable, la legalidad de la solución instaurada es más que discutible. Así lo han puesto de manifiesto un gran número de juristas. Las opiniones llegan incluso desde Hong Kong. El profesor y abogado Sunny S.H. Chan considera que la doctrina del facilitador es insostenible por dos motivos: porque adoptar la complicidad sin una ley que así lo prevea, deduciéndola simplemente del concepto de autoría, conlleva inmensa ambigüedad e inseguridad; y porque extender la responsabilidad de los autores a los partícipes supone infringir el principio de que las infracciones y las sanciones tienen que estar definidas por Ley $^{27}$.

26 En esta sentencia, el TJUE responde una petición de decisión prejudicial que tiene por objeto la interpretación del artículo 101 TFUE y que se presenta en el contexto de un litigio que enfrenta a varias agencias de viajes lituanas con el Consejo de la Competencia de la República de Lituania, en relación con una decisión por la que éste condenó a dichas empresas al pago de multas por haber llevado a cabo prácticas anticompetitivas, concretamente haber coordinado entre sí los descuentos sobre los viajes vendidos a través del sistema E-TURAS.

Por una parte, se encontraba la empresa Eturas que no actuaba en el mercado de referencia, sino que se limitaba a administrar el sistema E-TURAS; y por otra parte se encontraban las agencias de viajes. La empresa Eturas era la encargada de coordinar al resto de empresas para aplicar los descuentos y las agencias de viajes actuaban conjuntamente para conseguir sus objetivos anticompetitivos. Como consecuencia, el Consejo de la Competencia declaró tanto a Eturas como a las agencias de viajes culpables de una infracción del artículo 101 TFUE, pero a la primera en concepto de facilitadora.

27 S.H. CHAN, Sunny (2016): 135. 
En definitiva, las razones por las que la teoría del facilitador no encaja felizmente en el Derecho administrativo sancionador español se resumen en una: la vulneración que conlleva del principio de legalidad administrativa sancionadora. En España, este principio es de una importancia extraordinaria en este ámbito. Tanta, que aparece proclamado en el art. 25.1 CE y "debe situarse mucho más cerca del principio de legalidad penal (...) que del principio de legalidad administrativa en general" ${ }^{\prime 2}$. Sin embargo, esta garantía no rige en la misma medida en el Derecho sancionador europeo y ello conlleva que la jurisprudencia europea en general y la más específica del facilitador de infracciones en particular sufra importantes problemas para su aplicación en nuestro Derecho.

En nuestro Derecho punitivo, el principio de legalidad sancionadora requiere que sea una Ley la que establezca cuáles son las infracciones y las sanciones que conllevan. Y, en segundo lugar, conlleva un mandato de certidumbre, basado en que las leyes tipifiquen de forma precisa ambos extremos, tanto infracciones como sanciones, para que así "se cumpla la finalidad de la norma sancionadora, es decir, indicarle al ciudadano, con la mayor claridad posible, cuál es la conducta que debe evitar para que no se le imponga la sanción prevista por la norma" ${ }^{29}$.

Podemos concluir entonces que el principio de legalidad administrativa sancionadora tiene una doble significación reiteradamente puesta de manifiesto por el Tribunal Constitucional y el Tribunal Supremo, pues comprende una garantía formal y una garantía material ${ }^{30}$. La primera garantía se traduce en la reserva de ley, de modo que es una Ley la que debe tipificar la infracción y atribuirle los castigos que correspondan, así como determinar otros aspectos importantes del régimen jurídico -sujetos a los que puede sancionarse, reglas para determinar la extensión de la sanción, la extinción de la responsabilidad, etc- ${ }^{31}$. Por otra parte, la garantía material conlleva la obligación del legislador de especificar de forma clara y precisa las conductas ilícitas y las consecuencias derivadas de las mismas. Esta segunda garantía, "resultante del principio de legalidad, se concreta en otro principio derivado del mismo que es el de tipicidad"32.

\footnotetext{
${ }^{28}$ HUERGO LORA, Alejandro, Las sanciones administrativas, Iustel, 2007, Madrid, p.368.

29 HUERGO LORA, Alejandro (2007): 366.

30 MUÑOZ MACHADO, Santiago, Tratado de Derecho Administrativo y Derecho Público General, Tomo IV. La actividad administrativa, Iustel, 2011, Madrid, p. 965.

31 REBOLLO PUIG, Manuel e IZQUIERDO CARRASCO, Manuel, "Derecho administrativo sancionador: caracteres generales y garantías materiales", Derecho Administrativo, Tomo II: Régimen jurídico básico y control de la Administración, dirigida por REBOLLO PUIG, Manuel y VERA JURADO, Diego José, Tecnos, 2016, Madrid, p. 205.

32 MUÑOZ MACHADO, Santiago (2011): 966.
} 
Tanto en el caso de la CAP de la Junta de Andalucía como en el caso de la $\mathrm{APB}$, la autoridad de competencia declaró la responsabilidad de una Administración Pública por infringir el art. 1 LDC. Sin embargo, aunque se admita que se puede sancionar a la Administración porque el art. 61 LDC considera sujetos infractores a las personas físicas o jurídicas que realizan las acciones u omisiones tipificadas como infracciones en la misma, no es menos cierto que la declaración de responsabilidad fue inesperada en ambos casos porque el art. 62 LDC establece que son infracciones el desarrollo o la realización de las conductas tipificadas, pero nada más que eso, no su facilitación.

La CNC y el TS actuaron así siguiendo a las autoridades administrativas y judiciales europeas, olvidando que existe una diferencia fundamental entre el Derecho administrativo sancionador de la Unión Europea y el español: mientras que en el primero el principio de legalidad administrativa sancionadora se flexibiliza hasta tal punto que, junto con la previsibilidad de la norma, hay que tener en cuenta el complemento de la jurisprudencia y la posible necesidad de asesoramiento jurídico; en el segundo, este principio es de una importancia tal que se traduce en un derecho fundamental de los ciudadanos que no admite tanta flexibilidad.

Por eso, a mi parecer, conforme a las exigencias de reserva de ley y tipicidad que derivan del principio de legalidad administrativa sancionadora, la interpretación llevada a cabo por la CNG para declarar la responsabilidad de la CAP y de la $\mathrm{APB}$, ratificada posteriormente por el TS, hace uso de la analogía para sancionar una conducta no prevista legalmente como infracción. Esto es, no se prevé en la LDC la posibilidad de que la Administración Pública -o cualquier otro sujeto- pueda ser sancionada por facilitar la realización de infracciones de competencia y, aun así, ha sido, en un caso, declarada responsable (CAP) y, en otro, incluso sancionada. Por tanto, a mi juicio, tanto las resoluciones de la CNG como las sentencias del TS son, en lo relativo a la declaración de responsabilidad de la Administración Pública, contrarias a la garantía del art. 25.1 CE.

\section{La aplicación del concepto de facilitador a la Administración}

Las conductas prohibidas por el art. 1 LDG y por el art. 101 TFUE "suelen ser llevadas a cabo o promovidas por empresas que buscan mejorar, afianzar o asegurar su posición en el mercado a través de comportamientos anticompetitivos". Por eso, "tradicionalmente, los destinatarios directos de las políticas de la competencia han sido las empresas, especialmente las más potentes económicamente hablando, que encontraban en la libertad absoluta del laissez faire, el caldo de cultivo más adecuado para alterar los mercados en beneficio particular". Sin embargo, de un tiempo a esta parte, cada vez se muestra con más claridad que también los agentes de carácter público pueden alterar con su actuación el libre juego de la competencia de manera 
más o menos consciente favoreciendo así a determinados operadores, en perjuicio del interés general que deben proteger. Como consecuencia, ya no es discutible el sometimiento de los entes públicos a la normativa de competencia, salvo en los casos legalmente previstos en los que se excluye su aplicación ex art. 4 LDG.

La duda que surge ahora es si cabe sancionar a la Administración Pública en concepto de facilitadora. La responsabilidad sancionadora de la Administración Pública, al igual que la del resto de personas físicas y jurídicas, se basa en los principios constitucionales de legalidad, personalidad de las sanciones y culpabilidad. Todos estos principios coinciden con los que rigen en Derecho Penal. Sin embargo, en el tema de la responsabilidad, surgen diferencias entre ambas ramas del Derecho, pues mientras que el Código Penal tipifica y diferencia las figuras del autor y partícipe, no ocurre igual con las Leyes administrativas en las que lo normal es que únicamente se tipifique y sancione la autoría de las infracciones, aunque como contrapunto el legislador suela tipificar un amplio número de conductas que podrían considerarse supuestos de autoría mediata o participación ${ }^{33}$.

Al no existir en el Derecho administrativo sancionador una regla general sobre autoría y participación ni darse en las leyes administrativas sancionadoras un patrón único de designación de responsables de las infracciones administrativas ${ }^{34}$, salvo que una Ley disponga lo contrario, sólo se podrán considerar responsables de las infracciones sus autores en sentido estricto. Sin embargo, como ya se ha dejado entrever, "la regla de que sólo son responsables de las infracciones sus autores admite excepciones legales. Y lo cierto es que, aunque minoritarias, hay leyes que sí que prevén la responsabilidad de los partícipes en una infracción ajena y, a veces, hasta de los encubridores" 35 . No es el caso de la LDC, por lo que en este ámbito "no se podrá sancionar a otros sujetos incluso aunque hayan realizado una conducta antijurídica y culpable ni siquiera en el caso de que guarde cierta relación con las conductas sí tipificadas" ${ }^{\prime 36}$. De lo contrario, se vulneraría el principio de legalidad y, por ende, el derecho fundamental del art. 25.1 CE.

33 REBOLLO PUIG, Manuel, IZQUIERDO CARRASCO, Manuel, ALARCÓN SOTOMAYOR, Lucia y BUENO ARMIJO, Antonio Ma ${ }^{\mathrm{a}}$, Derecho Administrativo Sancionador, Lex Nova, 2010, Valladolid, p. 260.

34 PASCUAL MORCILLO, Álvaro, "El cooperador necesario en las infracciones de la ley de defensa de la competencia", Problemas prácticos y actualidad del Derecho de la Competencia, coordinada por RECUERDA GIRELA, Miguel Ángel, Civitas, 2015, Cizur Menor (Navarra), p. 118.

35 REBOLLO PUIG, Manuel, "Responsabilidad de los autores de las infracciones y los partícipes", Revista vasca de Administración Pública, no especial 99-100, 2014, p. 2536.

36 REBOLLO PUIG, Manuel, "Los principios de legalidad, personalidad y culpabilidad en la determinación de los responsables de las infracciones", Régimen jurídico básico de las Administraciones Públicas, coordinada por REBOLLO PUIG, Manuel, LÓPEZ BENITEZ, Manuel y CARBONELL PORRAS, Eloisa, Iustel, 2015, Madrid, p. 845. 
Pues bien, aunque se acepte que cabe sancionar al facilitador cuando una Ley así lo permita, sigue surgiendo la duda de si puede sancionarse a la Administración en tal concepto cuando actúa como poder público, tal y como ya se planteó en su momento el Abogado General Nils Wahl, en las Conclusiones presentadas el 21 de Mayo de 2015 a propósito del caso Treuhand: "Una sociedad que no ejerce presión competitiva sobre los miembros del cártel ¿puede ser cómplice de una infracción de la prohibición de carteles?". Es el tema central en torno al que han girado estas líneas. Cierto sector doctrinal considera que sí, que no existe inconveniente porque "para que una conducta caiga bajo la prohibición antitrust es necesario y suficiente que tenga aptitud objetiva para restringir la competencia" 37 , siendo indiferente la condición jurídica del sujeto que la realiza y de su rol en el mercado de que se trate. Mientras que otra facción de la doctrina se mantiene firme al considerar que una Administración Pública, cuando ejerce potestades de imperium, no puede ser considerada operador económico, por lo que por mucho que se exceda o extralimite en el ejercicio, no puede ser sancionada en virtud de la LDC, cuyos preceptos se dirigen a empresas.

\section{CONCLUSIONES}

Aclarada la cuestión del sometimiento de la Administración Pública a la normativa de defensa de la competencia, ha resultado necesario aclarar los mecanismos con que cuenta la autoridad de la competencia para reaccionar ante una conducta administrativa anticompetitiva. En el caso de tratarse de una conducta materializada en un acto administrativo o en un reglamento, procede su impugnación ante la jurisdicción contencioso-administrativa ex art. 5.4 LCNMC. Es en el caso de tratarse de una conducta puramente material donde surgen algunos inconvenientes. El primero de ellos es la inaccesibilidad e ineficacia de la vía del mencionado art. 5.4 LCNMC, pues no existe ningún acto o reglamento que impugnar. El segundo de ellos es que el recurso contencioso-administrativo contra la vía de hecho del art. 30 LJCA es demasiado rígido, por lo que también resulta inaccesible. Y el tercero de ellos sólo surge cuando la conducta administrativa anticompetitiva no aparece tipificada como infracción en la LDC, como ocurre cuando esa conducta se basa en el auxilio y facilitación de las prácticas anticompetitivas de otros, pues en estos supuestos, si las autoridades administrativas de competencia deciden sancionar estarán vulnerando el principio de legalidad administrativa sancionadora y el derecho fundamental del art. 25.1 CE.

37 COSTAS COMESAÑA, Julio y HORTALÀ I VALLVÉ, Joaquim (2013): 20 y 21. 
Por tanto, o se amplían los términos en que se concibe actualmente el recurso contra la vía de hecho, o se tipifica la conducta propia de la figura del facilitador en las leyes sectoriales de aquellos ámbitos en que se demuestre necesario, como ha ocurrido en el sector de la competencia. No hacer nada supone resignarse a no perseguir las conductas administrativas materiales contrarias a la libre competencia, o peor aún, sancionar esas conductas sin las garantías que nuestro Derecho administrativo sancionador exige.

Consecuentemente, a mi parecer resulta necesario que la LDC tipifique expresamente una infracción y una determinada sanción administrativa para el caso de que la Administración, haciendo un uso inadecuado de sus potestades públicas, facilite una práctica contraria a la libre competencia. Además de conveniente, esto es perfectamente posible porque el principio de legalidad prohíbe que se sancione al que no ha llevado a cabo la conducta tipificada, pero no impide la posible responsabilidad por participar en la infracción de la que es autor otro, siempre que así lo prevea una ley y se sancione al partícipe por su propia conducta.

En definitiva, sólo modificando la LDG será posible lograr que el Derecho de la competencia cumpla de forma más efectiva su finalidad de expulsar de la vida económica la conducta de quienes actúan en el mercado que impida o sea apta para impedir que el proceso competitivo genere la eficiencia que le atribuye la teoría económica, pues con la legislación actual -aplicada correctamente- muchas de esas conductas quedan impunes. Trasladar, sin más, la figura del facilitador gestada en el Derecho comunitario al ordenamiento jurídico español supone vulnerar las exigencias más básicas de nuestro Estado de Derecho: que nadie pueda ser sancionado por una determinada conducta sin una ley previa que así lo disponga. Querer adaptarse rápido -y mal- a las exigencias de la Unión Europea conlleva destruir parte de la base de nuestro Derecho Administrativo Sancionador, es decir, el cardinal principio de legalidad administrativa sancionadora y todo lo que conlleva. Por no hablar de la escasa seguridad jurídica que se transmite a los ciudadanos cuando los órganos administrativos y judiciales de España actúan de esta manera. En nuestro país, a diferencia de lo que parece suceder en la Unión Europea, es necesario recoger de forma precisa y clara en las Leyes todas las conductas y todos los sujetos responsables que pueden ser sancionados, para que así los ciudadanos sepan a qué atenerse cuando actúan. Es lo mínimo que debe garantizar un Estado de Derecho. 


\section{BIBLIOGRAFÍA}

ARRANZ FERNÁNDEZ-BRAVO, Tomás y MOSCOSO DEL PRADO GONZÁLEZ, Luis, "Desarrollo reciente de la aplicación de las normas de defensa de la competencia a las Administraciones Públicas", Actualidad Jurídica Uría Menéndez, n 32, 2012, pp. 85-89.

BAÑO LEÓN, José María, "Libre competencia y Administración Pública: Derecho Administrativo y Derecho «antitrust»", Derecho de la regulación económica, Tomo IX. Comercio interior, dirigida por REBOLLO PUIG, Manuel, Iustel, 2013, Madrid.

GANedo ARRILlagA, María Pilar, "Derecho de la competencia, Administración y descentralización", Anuario multidisciplinar para la modernización de las Administraciones Públicas, n 9, 2014, pp. 147-160.

COSTAS GOMESAÑA, Julio y HORTALÀ I VALLVÉ, Joaquim, "La tipificación de la actividad de la Administración como facilitadora de cárteles", Anuario de la competencia, $\mathrm{n}^{\mathrm{o}}$ 1, 2013, pp. 13-32.

COSTAS COMESAÑA, Julio, "La sujeción de la actividad de la Administración al Derecho de la competencia", Estudios de derecho mercantil: Libro homenaje al Prof. Dr. Dr.h.c. Fosé Antonio Gómez Segade, coordinada por TOBÍO RIBAS, Ana María, Marcial Pons, 2013, Madrid, pp. 369-382.

DE STEFANO, Gianni, "AC-Treuhand Judgment: a broader scope for EU competition law infringements?", Journal of European Competition Law \& Practice, vol.6, $n^{\circ} 10,2015$, pp. 689-690.

GONZÁLEZ PÉREZ, Jesús, Comentarios a la Ley de la jurisdicción contencioso-administrativa, Civitas, 2016, Cizur Menor (Navarra), pp. 434-446.

GUILLÉN CARAMÉS, Javier, "La promoción de la competencia como refuerzo al ejercicio de la potestad sancionadora por parte de las autoridades de competencia: en especial, la impugnación de la actividad administrativa contraria al Derecho de la competencia", Cuestiones actuales del procedimiento sancionador en Derecho de la competencia, dirigida por GUILLÉN CARAMÉS, Javier, Civitas, 2013, Gizur Menor (Navarra), pp.369-399

HUERGO LORA, Alejandro, Las sanciones administrativas, Iustel, 2007, Madrid.

LÓPEZ MENUDO, Francisco, "Título III. Objeto del Recurso Contencioso Administrativo. Capítulo Primero. Actividad administrativa impugnable", Revista española de derecho administrativo, no 100, 1998, pp. 314-324. 
MARCOS FERNÁNDEZ, Francisco, ¿Pueden las administraciones públicas infringir la ley de defensa de la competencia cuando adquieren bienes o contratan servicios en el mercado?, Actas de Derecho Industrial y Derecho de Autor, vol. 29, 2009, pp. 840-865.

MARCOS FERNÁNDEZ, Francisco, “'Puede sancionarse a las Administraciones Públicas cuando no actúan como operador económico si restringen la competencia o promueven conductas anticompetitivas?, InDret, 2018, pp. 1-41.

MARCOS FERNÁNDEZ, Francisco, "Competencias autonómicas en los procesos de concentración de empresas", InDret, n 4, 2011, pp. 1-53.

MARCOS FERNÁNDEZ, Francisco, "El ámbito de aplicación subjetivo de la LDG y la conducta de la Junta de Andalucía en el cártel de la uva y del mosto de Jerez: Comentario a la RCNC de 6 de octubre de 2011, Exp. S/0167/09”, Revista de Derecho de la Competencia y la Distribución, no 11, 2012, pp. 253-276.

MARCOS FERNÁNDEZ, Francisco, "Título I. De la defensa de la competencia", Comentario a la ley de defensa de la competencia y a los preceptos sobre organización y procedimientos de la Ley de creación de la Comisión Nacional de los Mercados y la Competencia, coordinada por MASSAGUER FUENTES, Josep, $4^{\mathrm{a}}$ Edición, Civitas, 2015, Madrid, pp. 308-400.

MUÑOZ MACHADO, Santiago, Tratado de Derecho Administrativo y Derecho Público General, Tomo IV. La actividad administrativa, Iustel, 2011, Madrid.

ORTEGA BERNARDO, Julia, "¿Se puede sancionar a la Administración en el ámbito de la Defensa de la Competencia?", Almacén de Derecho, 31 de enero de 2017, recuperado de http://almacendederecho.org/

PASCUAL MORCILLO, Álvaro, "El cooperador necesario en las infracciones de la ley de defensa de la competencia", Problemas prácticos y actualidad del Derecho de la Competencia, coordinada por REGUERDA GIRELA, Miguel Ángel, Civitas, 2015, Cizur Menor (Navarra), pp. 111-135.

REBOLLO PUIG, Manuel e IZQUIERDO CARRASGO, Manuel, "Derecho administrativo sancionador: caracteres generales y garantías materiales", Derecho Administrativo, Tomo II: Régimen jurídico básico y control de la Administración, dirigida por REBOLLO PUIG, Manuel y VERAJURADO, Diego José, Tecnos, 2016, Madrid.

REBOLLO PUIG, Manuel, "La presunción de validez", Revista española de derecho administrativo, $\mathrm{n}^{\circ} 128,2005$, pp. 587-638.

REBOLLO PUIG, Manuel, "Los principios de legalidad, personalidad y culpabilidad en la determinación de los responsables de las infracciones", Régimen jurí- 
dico básico de las Administraciones Públicas, coordinada por REBOLLO PUIG, Manuel, LÓPEZ BENITEZ, Manuel y CARBONELL PORRAS, Eloisa, Iustel, 2015, Madrid, pp. 843-864.

REBOLLO PUIG, Manuel, "Reglamentos y actos administrativos ante el Tribunal de Defensa de la Competencia”, Estudios de derecho público económico: libro homenaje al Prof. Dr. D. Sebastián Martín-Retortillo, coordinada por COSCULLUELA MONTANER, Luis, Civitas, 2003, Madrid, pp. 719-742.

REBOLLO PUIG, Manuel, "Responsabilidad de los autores de las infracciones y los partícipes", Revista vasca de Administración Pública, no especial 99-100, 2014, pp. 2527-2546.

REBOLLO PUIG, Manuel, IZQUIERDO CARRASCO, Manuel, ALARCÓN SOTOMAYOR, Lucia y BUENO ARMIJO, Antonio Ma ${ }^{\mathrm{a}}$, Derecho Administrativo Sancionador, Lex Nova, 2010, Valladolid.

S.H. CHAN, Sunny, "AC-Treuhand: What is the ambit of cartel facilitators' liability?", European Competition Law Review, Issue 4, 2016, Thomson Reuters, pp. 133 138.

VALLERY, Anne y SCHELL, Caroline, "AC-Treuhand: Substantial Fines for Facilitators of Cartels", Fournal of European Competition Law \& Practice, vol. 7, n 4, 2016, pp. 254-257.

VERA JURADO, Diego, "Las sanciones entre Administraciones Públicas", Fusticia Administrativa, número extraordinario, 2001, pp. 53-74. 